\title{
ARTICLE \\ Efficient Methodology for Design of Industrial Blast Resistant Electrical Substations and Control Buildings
}

\section{Osama Bedair*}

415-249 Craig Henry Drive, Ottawa, Ontario, Canada

\begin{tabular}{|c|c|}
\hline ARTICLE INFO & ABSTRACT \\
\hline Article history & \multirow{13}{*}{$\begin{array}{l}\text { This paper describes economical strategies to design blast resistant } \\
\text { electrical substations and control buildings that are commonly used at } \\
\text { industrial plants. Limited literature addressed design aspects for this class } \\
\text { of buildings. Furthermore, little guidelines are available in practice to } \\
\text { regulate this type of steel construction. The first part of the paper over- } \\
\text { views the architectural and structural layouts of electrical buildings. Blast } \\
\text { resistance requirements for occupied control buildings are also discussed. } \\
\text { Simplified multiple degrees of freedom (MDOF) dynamic model is also } \\
\text { illustrated that can be utilized for analysis of the blast resistant buildings. } \\
\text { The economical aspects and cost savings resulting in using mobile blast } \\
\text { resistant buildings are discussed. The article also highlights the engineer- } \\
\text { ing challenges that are encountered in design of mobile electrical facil- } \\
\text { ities. The transportation procedure and design requirements are briefly } \\
\text { described. Guidelines are proposed to calculate the center of mass of the } \\
\text { building combined with interior equipment. The proposed design concept } \\
\text { for electrical and control buildings is cost effective and can be imple- } \\
\text { mented in industry to reduce projects cost. }\end{array}$} \\
\hline Received: 22 February 2021 & \\
\hline Accepted: 11 March 2021 & \\
\hline Published Online: 30 March 2021 & \\
\hline Keywords: & \\
\hline Industrial buildings & \\
\hline Dlu & \\
\hline Electrical substations & \\
\hline Control building & \\
\hline Steel modules & \\
\hline Analyzer buildings & \\
\hline Steel design & \\
\hline Mobile industrial facilities & \\
\hline
\end{tabular}

\section{Introduction}

Electrical substations, analyzer buildings and control buildings are essential facilities that are required in the operation of industrial plants. These buildings host electrical, instrumentation and mechanical equipment that are required for plants operation. The cost of these buildings is substantial and carful design procedures must be used to economize the design and optimize the capital cost. In surface mining projects, federal and provincial legislations require operators to submit plan showing the restoration of disturbed lands to its original state for future use after completion of mining and oil exploration in order to minimize environmental hazards. Therefore, it is econom-

ical to design electrical and control buildings as mobile facilities to be utilized at several locations as the projects expand.

The proposed design concept in order to minimize the project cost is summarized in the flow chart shown in Figure 1. In stage (I), the building is modularized at the fabrication shop. The building at this stage is fully fabricated and commissioned off-site. Instrumentation equipment and electrical cabinets are then installed at the fabrication yard. This approach improves work quality and productivity especially in remote site locations with harsh weather condition, since construction and commissioning are minimized. Furthermore, multidisciplinary work of various activities can be undertaken in parallel. Thus the proposed

*Corresponding Author:

Osama Bedair,

415-249 Craig Henry Drive, Ottawa, Ontario, Canada;

Email:obedair@gmail.com 
procedure minimizes overall project cost and schedule. In stage (II) the building is transported and delivered to the site as functionally complete unit. The type of transportation vehicle depends upon the overall weight of the building and the access roads to the plant. Furthermore, the modularized building size should not exceed the shipping envelope allowed by the provincial transport regulations. In most cases the envelope is limited to $7.3 \mathrm{~m}$ wide $\mathrm{x} 36$ $\mathrm{m}$ long $\times 7.8 \mathrm{~m}$ high. Also, the building height should be minimized in order to reduce the material cost. At stage (III) the building is lifted and installed on foundation for a predetermined period of time. At the end of the project duration, the electrical building is decommissioned then jacked and relocated to another plant area, as denoted by Stages (IV) and (V). Note that boxes in the flow chart with green color denote stages that require transportation of the building.

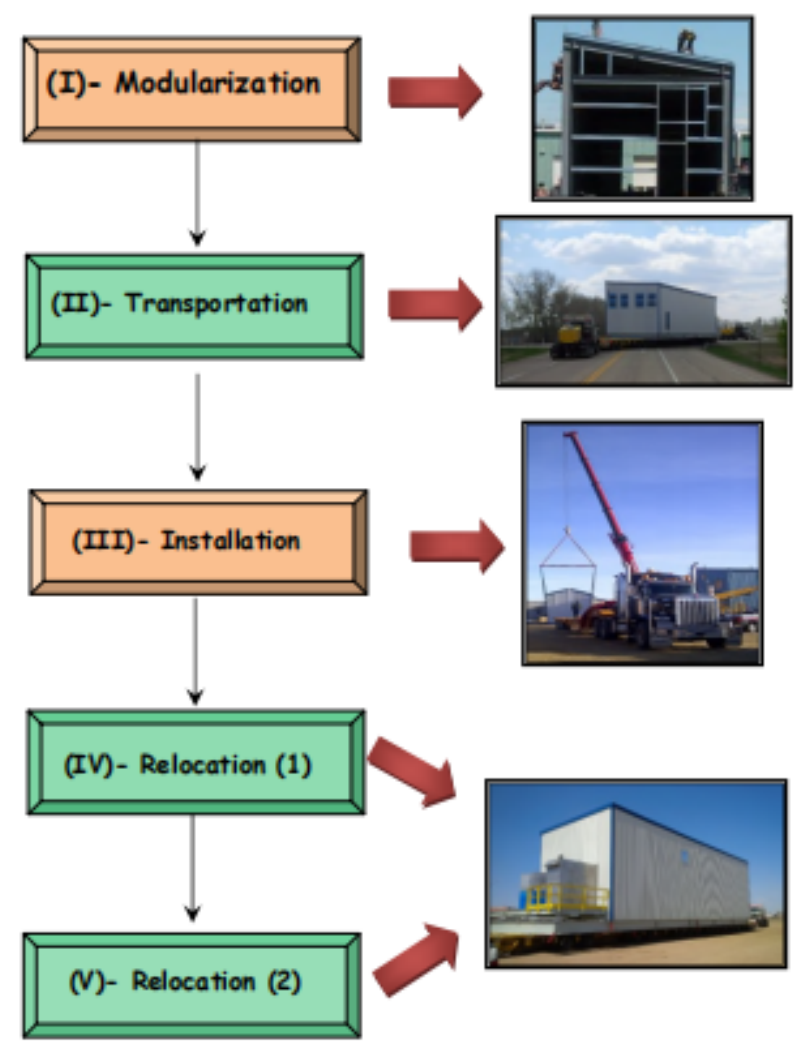

Figure 1. Sequence of Relocating and Installing Mobile Buildings

The engineering phase that would be required by EPC companies to design effective relocation methodology for industrial facilities might take several years depending upon the size and layout of the buildings. It must be noted that failures during relocation of the buildings may result in severe financial losses. Accordingly, proper engineering planning and execution is required to detail the disassembly and re-installation methodologies.
Limited investigations addressed structural design of mobile buildings. Bedair ${ }^{[1-6]}$ presented cost effective procedures for steel fabrication and design of oil\&gas and mining facilities. Other studies were conducted to investigate impact of mobile vehicles used in mining projects, e.g. Newman, et al. ${ }^{[7]}$, Burt and Caccetta ${ }^{[8]}$, Alarie and Gamache ${ }^{[9]}$ and Soumis ${ }^{[10]}$. However, the primary attention was given to mining facilities at permanent locations. Little information is published that address engineering design of mobile structures. Much of the design codes and engineering standards such as AISC ${ }^{[11]}$, AISI ${ }^{[12]}, \mathrm{ASCE} /$ SEI ${ }^{[13]}$, AASHTO ${ }^{[14]}$, CSA-S136 $6^{[15]}$, CSA -S16 ${ }^{[16]}, \mathrm{NBC}$ ${ }^{[17]}$, Eurocode-3 ${ }^{[18]}$, PIP ${ }^{[19]}$ and Ziemian ${ }^{[20]}$, regulate design of permanent structures.

This paper bridges the gap and provides engineering requirements for design of mobile industrial buildings. The intention is to present cost effective concept for design of mobile buildings that can be utilized in industrial projects. The first part deals with conventional buildings and the second part deals with blast resistant category. The first type is commonly used in non-hazard plant areas while the second type is capable resist petrochemical explosions. The paper also presents a practical multiple degrees of freedom (MDOF) model to determine dynamic response of buildings subjected to far field blast loads. Mathematical derivations to compute displacements and base shear are then presented. The paper provides useful tools that can be used in industry to calculate the dynamic response with little computation effort/cost compared to numerical finite element (FE) method or computational fluid dynamic (CFD) procedures. The described approach can also be used to optimize the building design and reduce project capital costs. It should be emphasized that the scope of the paper is limited to structural and construction aspects. The electrical and instrumentation designs are not covered by this paper.

\section{Building Material}

There are no general guidelines or rules for the structural material selection in the construction of mobile buildings. Precast concrete panels have been used in several industrial plants. Concrete buildings provide better fire resistance while steel construction provides better ductility and ultimate resistance for seismic and blast loadings. Low carbon steel material exhibits large inelastic strain capacity or deformation ratio. Higher strength steel may not offer sufficient ductility and hence is not economical to use. Concrete has limited ductility and low tensile strength. Furthermore, concrete panels may not be suitable to modularize at fabrication yard or transportation to other site locations. 
Mobile blast resistant buildings BRB must be capable to absorb and dissipate blast explosion energy while maintaining structural integrity. Building envelope must have adequate ductility and strength to resist lateral loads resulting from blast loads. Therefore, brittle materials such as unreinforced concrete, bricks, timber may not offer adequate blast resistance. In addition, other construction material such as timber or wood could be a fire hazard. Economical design can be achieved by locating the building in a zone with the least blast overpressure without interferences with Electrical or instrumentation functionality. In addition, the building design must utilize the efficient engineering and construction practices.

\section{Electrical Building Layout}

Electrical buildings envelope is determined according to the interior electrical, instrumentation and mechanical equipment sizes and spacing requirements. Figure 2 shows a typical example for interior layout of electrical buildings. Figure 2a shows rows of vertical electrical cabinets supported by the floor framing. Figure $2 b$ shows suspended cable trays inside an electrical house. Vertical tie rods connected to the main framing are commonly used to support cable trays and are spaced every $6 \mathrm{~m}$. Figure $2 \mathrm{c}$ shows vertical instrumentation cabinets that are supported on the side beams.

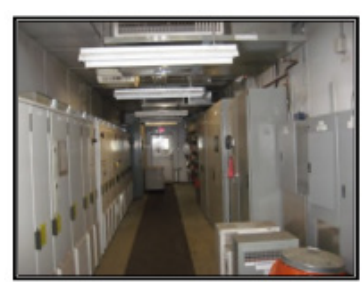

a) Electrical Cabinets

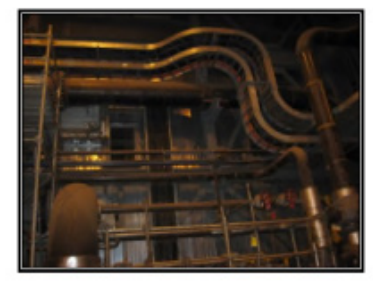

b) Suspended Electrical Cable Trays

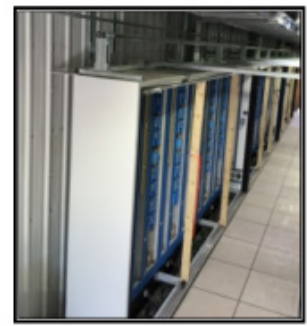

c) Wall Instrumentation Cabinets

Figure 2. Interior Photos of the Electrical and Control Buildings

Figure 3 shows typical electrical building layout. Relocatable electrical buildings must be supported by steel skid to cope with shipping and transportation requirements. Typical skid layout is shown in Figure 3a.The longitudinal skid beams are bolted to transverse beams that support the floor. The spacing of the transverse beams is determined according to the floor loadings. The skid must be designed to accommodate lifting and transportation loads. Removable or permanent lifting lugs are installed along the columns gridlines. The interior electrical building layout is illustrated in Figure $3 \mathrm{~b}$. The primary framing consists of steel columns, inclined rafters, longitudinal and transverse beams as shown by section B-B of Figure 3c. Interior beams across the full width of the building can be used to support electrical cable trays and HVAC ducts as required and shown by electrical/mechanical design drawings. It is recommended to use interior cantilever beam supports at various levels to maximize the useable floor space. The spacing between these supports should not exceed $6 \mathrm{~m}$. Girts and purlins are used to connect external cladding. The building gridlines are located along the column centerlines. It is recommended to use standard $6 \mathrm{~m}$ column intervals and vary end bays (as denoted by $\mathrm{S}$ in Figure $3 \mathrm{~b}$. Building width can be determined based on cabinet number and space requirements. If platforms are attached to the building, they must fall within the transportation envelope. Figure 3d shows side elevation (A) of the building. Side wall penetrations might be provided to allow passage of cable trays to external facilities. However wall penetration should be limited to maximum of $25 \%$ of overall wall area.

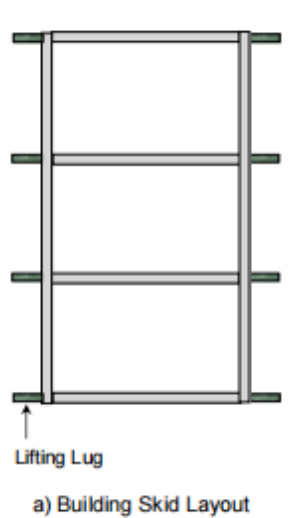

a) Building Skid Layout

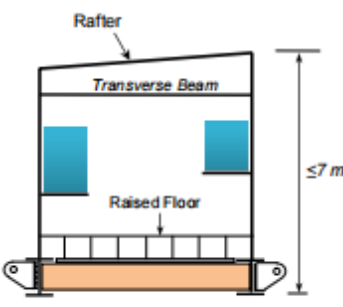

c) Section B-B

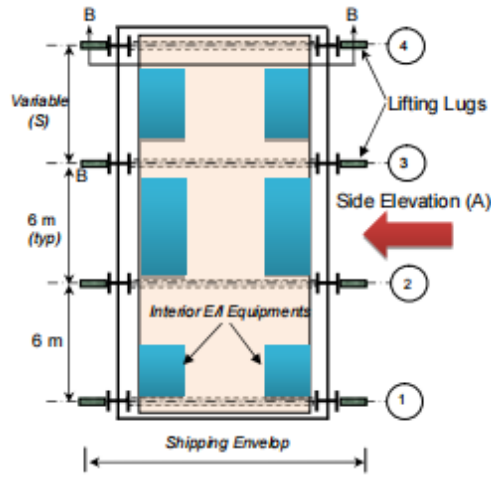

b) Electrical Building Interior Plan

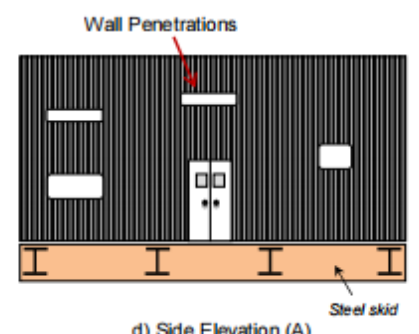

d) Side Elevation (A)
Figure 3. Typical Electrical Building Structural System 
It is also economical from fabrication perspective to use standard member sizes to limit wide variations in steel sections that may result in substantial increase in the building cost. For example, column sizes can be limited to W360 (W14), rafters and perimeter skid beams to W460 (W18), beams and equipment supports to W250 (W10).

Raised floor is provided to meet electrical area classification and installation access to provide under-floor cable tray passage. Figure 4 shows typical raised floor framing layout in electrical buildings. The lower level is used to run cable trays and storage of spare parts. Typical raised floor height is 600 millimeters. Strut sub-frames grids are provided under the cabinets to support the weight. The finished floor is constructed with square, removable, vinyl covered panels using interlocking grid struts.

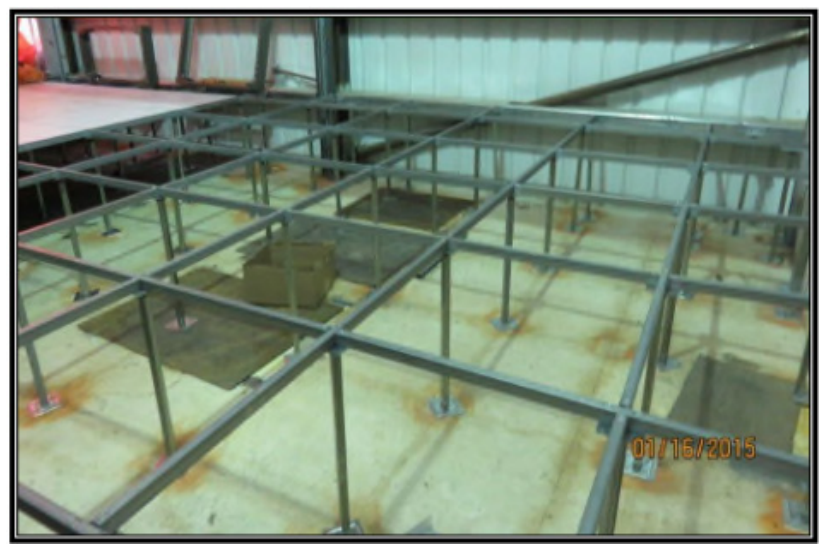

Figure 4. Raised Floor Framing Layout

\section{Firewall and Blast Barriers}

Fire requirement shall be determined in accordance with local building codes and in compliance with plant process safety and loss prevention manuals. It is beneficial to use firewalls to protect control buildings or substations adjacent to electrical transformers from fire or explosions. Placement of firewalls is compulsory if the building contains large penetrations. The material of the firewall could be concrete masonry units $\mathrm{CMU}$ or galvanized steel panels. The cost of steel panels could be much more expensive than ordinary CMU wall. Other types have recently evolved in the construction market using different material technologies to increase fire-rating. As an example, Figure 5 shows typical layout of firewall arrangement separating electrical building from three external electrical transformers. Section A-A shows the elevation of CMU wall supported by concrete strip footing. Dowel bars are extended from to the foundation to the wall in order to enhance the flexural base capacity. The size and spacing of the dowel bars depend upon the height of the wall.

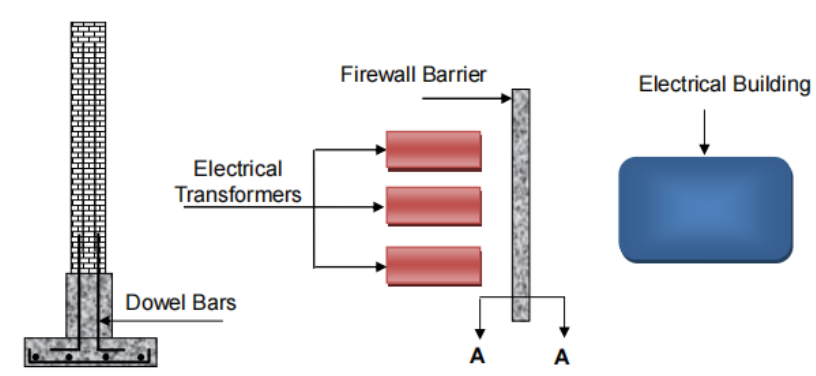

SECTION A-A

Figure 5. Typical Firewall Barriers

Limited information is available on damage assessments of buildings protected by blast or fire walls. Damage assessment of control buildings due to blast explosions requires accurate prediction of blast loads generation and transfer through the structural members. Little guidelines are also available to predict the reduced level of pressures and impulses behind blast wall. The most popular procedures to calculate blast loadings are based on empirical relationships. The derived equations are developed by assuming no intermediate obstacles between the explosion source and the target. If a blast barrier is used to protect personnel or a structure behind it, the actual blast loading environment will be significantly reduced for some distance behind the barrier. Coughlin, et. al. ${ }^{[21]}$ investigated the response of concrete barriers commonly used to protect essential structures against terrorism actions. Five portable concrete vehicle barriers were tested under satchel sized contact charge explosives. The authors also developed a numerical study using FE method to validate tests data. Other numerical simulation by Remennikov, et al ${ }^{[22,23]}$ highlighted the effects of adjacent structures on blast loads of buildings located in urban terrain. The authors used neural network-based techniques and experimental data to develop contour plots of overpressure and impulse adjustment factors in order to estimate effectiveness of blast barriers.

\section{Mobile Blast Resistant Buildings}

Blast resistant buildings $\mathrm{BRB}$ are used as shelters to protect personnel working in potentially explosive hazardous areas at industrial plants. Examples of BRB in petrochemical plants are; operator service building, control room, electrical and mechanical buildings, warehouse, administration building, medical and fire stations. The design of these buildings must meet both governing codes and owners safety requirements that are dictated by petroleum industry. Blast resistant buildings BRB are designed as modular steel structures or in some cases or pre-cast concrete. Temporary BRB or trailers are also used during 
revamp construction projects or turnaround operations to protect people working within process zones in case of explosions.

Blast resistant buildings BRB are critical structures that are used to reduce human fatalities and damages to critical industrial facilities. Mitigation techniques must ensure public safety in the event of accidental explosions. Industrial buildings layout varies significantly depending upon the process design and other engineering disciplines requirements. Complexity in the layout varies from a cubical to major facilities encompassing several buildings. This makes generalized rules for blast resistant design very difficult to achieve. The assessment of blast loading effects on BRB is required during the detailed design phase. The appropriate approach is to perform accurate and reliable evaluation of the blast pressure and impulse acting on the structure. Height of the building should be minimized in order to reduce the cost. The building should be designed using two independent vertical and horizontal resisting systems.

Blast buildings are classified as occupied and non-occupied buildings. Occupied buildings that are located within the process zones such as control rooms, substations, remote I/O building, should be designed as blast resistant buildings in order to maintain operation during explosion or in the post-explosion stage.

\subsection{Petrochemical Explosions}

Refineries and petrochemical plants have the potential to release clouds of flammable vapor that if ignited produce explosive loads. These explosions results in fast and considerable pressure increase as well as high temperatures. The shock wave propagates with a given speed, magnitude and duration. The properties of gas explosions depend on fuel-oxygen cloud concentration and type of ignition source. Pressure vessel burst is another class of explosion that creates critical hazards at chemical processing facilities. This type of explosions results in both air-blast and fragmentation hazards. The characteristics of blast wave depend upon the vessel geometry. As illustration, side blasts on vessel with cylindrical geometry is stronger than the ends that may create non-circular pressure contours. The directional effects diminish with distance as the expanding shock wave approaches a spherical shape. The U.S Department of Defense ${ }^{[24]}$, published a manual that contains collection of data for explosions related to munitions, manufacturing, handling and storage facilities. Other references such as; American Society of Civil Engineer ${ }^{[25]}$, Canadian Standard Association ${ }^{[26]}$ and Process Industry Practices ${ }^{[27]}$ also provide empirical parameters for general blast loading resulting from bombs, fires and accidental explosions applied to residential and industrial buildings.

The orientation of the building relative to the blast explosion source is critical in determining the magnitude of the blast load intensity on each building side. Figure 6 shows the blast pressure variation $(p)$ with time $(t)$ on the building walls $\left(\mathrm{W}_{1}-\mathrm{W}_{4}\right)$. Note that building walls are labeled according to the blast source location. $\mathrm{W}_{1}$ is wall facing the blast, $\left(\mathrm{W}_{2} \& \mathrm{~W}_{3}\right)$ are the side walls and $\left(\mathrm{W}_{4}\right)$ is the rear wall.

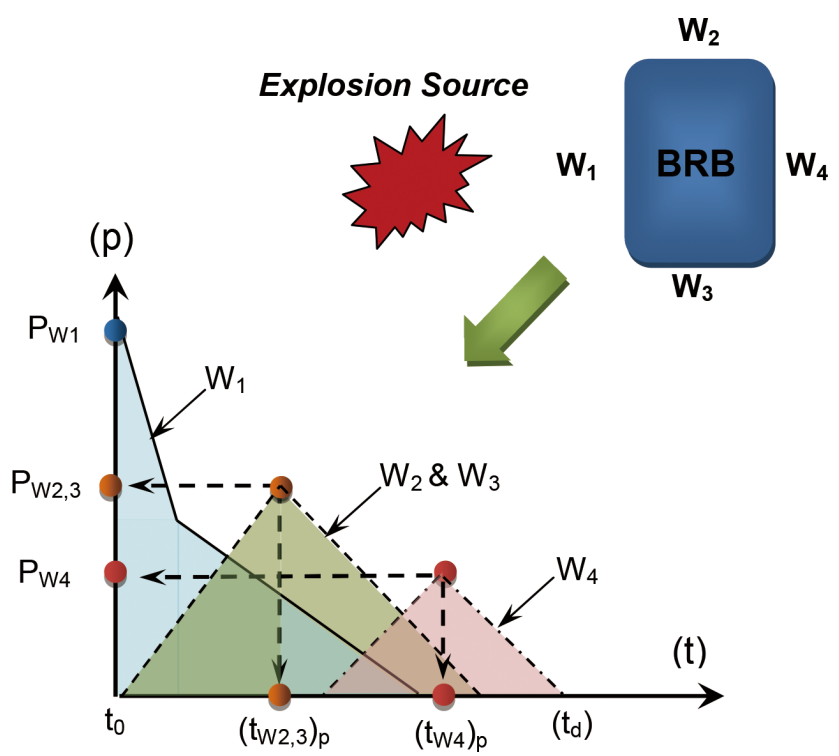

Figure 6. Blas Pressure Variation with Time (t) on Walls $\left(\mathrm{W}_{1}-\mathrm{W}_{4}\right)$

The idealized blast pressure of the wall facing the blast $\left(\mathrm{W}_{1}\right)$ is shown by the blue color. The reflected peak overpressure is denoted by $\left(\mathrm{P}_{\mathrm{W}_{1}}\right)$ at time $(\mathrm{t})=\left(\mathrm{t}_{0}\right)$. The blast pressure envelop on side walls $\left(\mathrm{W}_{2} \& \mathrm{~W}_{3}\right)$ is shown by the green triangle. Note that side walls $\left(\mathrm{W}_{2}\right)$ and $\left(\mathrm{W}_{3}\right)$ experience less blast loading compared $\left(\mathrm{W}_{1}\right)$ since these walls are not facing the blast. This is due to the gradual loss of blast intensity as the wave travels along the length of the building. The peak pressure on these walls is denoted by $\left(P_{\mathrm{w} 2,3}\right)$ at time $(t)=\left(t_{\mathrm{w} 2,3}\right)_{\mathrm{p}}$, as shown in Figure 6. As the blast wave reaches the far end of the wall, the overpressure at the near end is reduced. The blast envelop on the rear wall $\left(\mathrm{W}_{4}\right)$ is shown by the pink triangle in Figure 6. The peak pressure acting on this wall is reduced to $\left(\mathrm{P}_{\mathrm{W} 4}\right)$ at time $(\mathrm{t})=\left(\mathrm{t}_{\mathrm{w} 4}\right)_{\mathrm{p}}$

\subsection{Simplified MDOF Blast Model}

Global dynamic analysis for BRB is required to determine overall peak dynamic displacements and stresses due to application of the blast loads. The common design procedures used in practice for blast resistant buildings BRB 
is simplified by using a single degree of freedom (SDOF) dynamic system. In this approach, the local dynamic response of structural members is determined in isolation. The global response of BRB frame is not determined using (SDOF) model. Therefore, alternative procedure is required to determine the global dynamic response. This section presents multiple degrees of freedom MDOF model that can be used to predict the global dynamic response of BRB.

Consider a typical building shown in Figure 7 exposed to blast explosion. The building contains three rows of electrical cabinets. The explosion source for this building is initiated from the left side as shown. The BRB primary framing consists of steel columns, longitudinal and transverse beams. The column spacing is denoted by (S). Intermediate girders support interior ducts, cable trays and service platforms/catwalks. They also provide lateral restraints to columns and enhance the connection flexibility. The ground elevation GE is measured from the bottom of the steel skid. Raised floor height measured from GE is denoted by $\left(\mathrm{h}_{1}\right)$. The separation between the BRB floor and skid floor is approximately ( $2 \mathrm{ft})$. This spacing is normally utilized to place the cable trays and spare parts. Removable floor panel system is used to facilitate access to the electrical wiring. The skid floor is located on the same elevation as the flange of the skid beams.
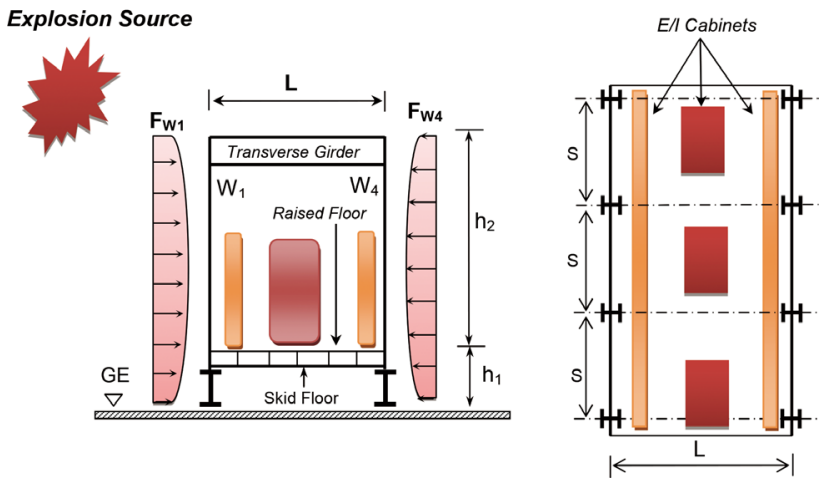

Figure 7. Blast Resistant Building Structural Layout

The idealized structural model is shown is illustrated in Figure 8 . The raised floor mass is denoted by $\left(\mathrm{m}_{1}\right)$ and is assumed to be uniformly distributed across the width (L). The equivalent floor stiffness is approximated by $\left(\mathrm{EI}_{1}\right)_{\text {eqv }}$ at floor level $\left(\mathrm{h}_{1}\right)$. Dead load at this elevation shall include weight of (EI) cabinets, gas cylinders, cable trays, spare parts, interior ducts and permanent fixtures. The mass and equivalent stiffness at the upper level $\left(\mathrm{h}_{2}\right)$ are denoted by $\left(\mathrm{m}_{2}\right)$ and $\left(\mathrm{EI}_{2}\right)_{\text {eqv }}$. Dead load at this elevation shall include suspended cable trays, ducts, elevated equipment and electrical fixtures. The roof and supporting purlins can be included in the calculation of the $\left(\mathrm{EI}_{2}\right)_{\text {eqv }}$ Note that HVAC units mounted on the roof should be included in the calculation of $\left(\mathrm{m}_{2}\right)$.
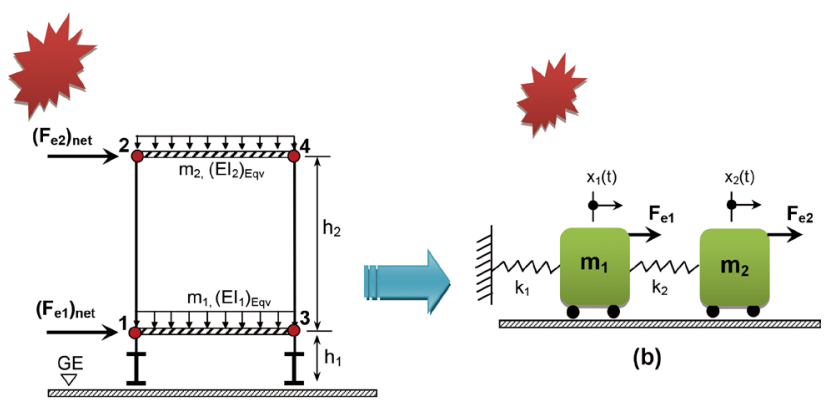

(b)

(a)

Figure 8. Simplified Equivalent Dynamic (MDOF) Model

Blast design is characterized by impact loads initiated by the blast wave followed by a time dependent pressures that occur due to thermal effects. The net blast forces are lumped at the joints and are approximated as follow:

$$
\left[\begin{array}{c}
F_{e 1} \\
F_{e 2}
\end{array}\right]_{n e t}=\left[\begin{array}{cc}
\left(h_{1}+\frac{h_{2}}{2}\right) & 0 \\
0 & \frac{h_{2}}{2}
\end{array}\right]\left[\begin{array}{l}
\left(F_{w 1}-F_{w 4}\right) \\
\left(F_{w 1}-F_{w 4}\right)
\end{array}\right]
$$

The equivalent two degrees of freedom spring-mass oscillator system is illustrated in Figure 8. Note that $\left\{\mathrm{x}_{1}(\mathrm{t})\right.$, $\left.\mathrm{x}_{2}(\mathrm{t})\right\}$ denote the time varying displacement measured from the center of mass. The spring stiffness of each mass are denoted by $\left\{\mathrm{k}_{1}, \mathrm{k}_{2}\right\}$, respectively. The governing differential equations are given in the following matrix form:

$\left[\begin{array}{ccc}m_{1} & k_{1} & -k_{2} \\ m_{2} & k_{2} & 0\end{array}\right]\left[\begin{array}{cc}x_{i}^{\bullet}(t) & x_{\dot{*}}^{*}(t) \\ x_{1}(t) & {\left[x_{2}(t)-x_{I}(t)\right.}\end{array}\right]=\left[\begin{array}{l}F_{e l}(t) \\ F_{e 2}(t)\end{array}\right]$

Where $\mathrm{x}_{\mathrm{i}}^{*}(\mathrm{t})$ and $\mathrm{x}_{\mathrm{i}}(\mathrm{t})$ are the acceleration velocity of the idealized mass due to blast loading.

The natural frequency of the building frame is determined by setting the right hand sides of Equation (2) to zero. For this condition, the system undergoes free vibration. The non-trivial solution is obtained by setting the determinant of the coefficient to zero. This yields the following characteristic equation:

$$
\left[\begin{array}{lll}
\omega^{4} & \omega^{2} & 1
\end{array}\right]\left[\begin{array}{c}
1 \\
-\delta \\
\beta
\end{array}\right]=0
$$

Where: 
$\delta=\left(\frac{k_{1}+k_{2}}{m_{1}}+\frac{k_{2}}{m_{2}}\right), \quad \beta=\frac{k_{1} k_{2}}{m_{1} m_{2}}$

The natural frequency of the structure is solution of Eq. (3) and is given by:

$\omega_{1}=\sqrt{\frac{1}{2}\left(\delta-\sqrt{\delta^{2}-4 \beta}\right)}, \quad \omega_{2}=\sqrt{\frac{1}{2}\left(\delta+\sqrt{\delta^{2}-4 \beta}\right)}$

The corresponding natural period $\left\{\mathrm{T}_{1}, \mathrm{~T}_{2}\right\}$ are given by:

$$
T_{1}=\frac{2 \pi}{\omega_{1}}, \quad T_{2}=\frac{2 \pi}{\omega_{2}}
$$

Determination of the building response due to blast loading requires the solution of coupled differential Eq. (2) that can be transformed into system of uncoupled equations by expressing the solution in form of generalized functions $\mathrm{z}(\mathrm{t})$ with normal or orthogonal modes as follow:

$\left[\begin{array}{l}x_{1}(t) \\ x_{2}(t)\end{array}\right]=\left[\begin{array}{ll}a_{11} & a_{12} \\ a_{21} & a_{22}\end{array}\right]\left[\begin{array}{l}z_{1}(t) \\ z_{2}(t)\end{array}\right]$

Where $\left\{\mathrm{z}_{1}(\mathrm{t}), \mathrm{z}_{2}(\mathrm{t})\right\}$ are orthogonal time varying functions that describe vibration mode subject to blast excitation and $\left\{\mathrm{a}_{\mathrm{ij}}\right\}$ are the associated coefficients that determine the contribution of each mode. Substituting these functions into Eq.(2) results into the following normalized differential equations

$$
\left[\begin{array}{cc}
z_{1}^{\bullet \bullet}(t) & z_{1} \\
z_{2}^{\bullet \bullet}(t) & z_{2}
\end{array}\right]\left[\begin{array}{cc}
1 & 1 \\
\omega_{1}^{2} & \omega_{2}^{2}
\end{array}\right]=\left[\begin{array}{l}
P_{1}(t) \\
P_{2}(t)
\end{array}\right]
$$

Where:

$$
\left[\begin{array}{l}
P_{1}(t) \\
P_{1}(t)
\end{array}\right]=\left[\begin{array}{lll}
\varphi_{11} & & \varphi_{12} \\
\varphi_{21} & & \varphi_{22}
\end{array}\right]\left[\begin{array}{l}
F_{e 1}(t) \\
F_{e 2}(t)
\end{array}\right]_{n e t}
$$

Where $\left(\varphi_{\mathrm{ij}}\right)$ denote the normalized vibration modes that are described by the following compacted form:

$$
\varphi_{i j}=\frac{a_{i j}}{\sqrt{\sum_{k=1}^{n} m_{k} a_{k j}^{2}}}
$$

The solution of the uncoupled differential Eq. (8) can be obtained numerically to determine the displacement profile. An upper limit for the maximum response can be obtained by adding the absolute values of the maximum modal contributions. This can be attained by replacing $\left\{\mathrm{z}_{1}, \mathrm{z}_{2}\right\}$ by $\left\{\mathrm{z}_{1 \max }, \mathrm{z}_{2 \max }\right\}$ and adding the absolute values, as follow:

$$
\left[\begin{array}{l}
y_{1 \max } \\
y_{2 \max }
\end{array}\right]=\left[\begin{array}{ll}
\varphi_{11} & \varphi_{12} \\
\varphi_{21} & \varphi_{22}
\end{array}\right]\left[\begin{array}{l}
\left|z_{1}(t)\right| \\
\left|z_{2}(t)\right|
\end{array}\right]_{\max }
$$

Equation (11) provides an upper limit to the maximum response at joints (1) and (2) of Figure 8. Determination of $\left(\mathrm{z}_{1 \max }\right)$ and $\left(\mathrm{z}_{2 \max }\right)$ can be determined from the following relation:

$$
\left[\begin{array}{c}
z_{1}(t) \\
z_{2}(t)
\end{array}\right]_{\max }=\left[\begin{array}{cc}
D L F_{1} & 0 \\
0 & D L F_{2}
\end{array}\right]\left[\begin{array}{c}
z_{1}(t) \\
z_{2}(t)
\end{array}\right]_{\text {Static }}
$$

where $\left(\mathrm{DLF}_{1}\right)$ and $\left(\mathrm{DLF}_{2}\right)$ are dynamic load factors. The displacements $\left\{\left(Z_{1}\right)_{\text {static }},\left(Z_{2}\right)_{\text {static }}\right\}$ are determined from:

$\left(z_{1}\right)_{\text {Static }}=\frac{P_{1}(t)}{\omega_{1}^{2}}, \quad\left(z_{2}\right)_{\text {Static }}=\frac{P_{2}(t)}{\omega_{2}^{2}}$

Alternatively, the square root of the sum of the squares of the modal contributions provides reasonable approximation to the maximum displacement as follows:

$\left[\begin{array}{c}y_{1}^{2} \\ y_{2}^{2}\end{array}\right]_{\max }=\left[\begin{array}{cccc}\varphi_{11}^{2} & \varphi_{12}^{2} & 0 & 0 \\ 0 & 0 & \varphi_{21}^{2} & \varphi_{22}^{2}\end{array}\right]\left[\begin{array}{c}z_{1}^{2}(t) \\ z_{2}^{2}(t) \\ z_{1}^{2}(t) \\ z_{2}^{2}(t)\end{array}\right]_{\max }$

Having determined the maximum dynamic displacements and associated modal shapes, the maximum column shear forces under blast loading can be determined using the following;

$V_{i j}=z_{j \max }\left(\varphi_{i j}-\varphi_{i-1, j}\right) \quad k_{i}$

Equation (15) can be expanded for the idealized model as follows:

$\left[\begin{array}{c}V_{11} \\ V_{12} \\ V_{21} \\ V_{22}\end{array}\right]=\left[\begin{array}{cccc}\left(\varphi_{11}\right)_{k_{1}} & 0 & 0 & 0 \\ 0 & \left(\varphi_{12}\right)_{k_{1}} & 0 & 0 \\ 0 & 0 & \left(\varphi_{21}-\varphi_{21}\right)_{k_{2}} & 0 \\ 0 & 0 & 0 & \left(\varphi_{22}-\varphi_{12}\right)_{k_{2}}\end{array}\right]\left[\begin{array}{c}z_{1}(t) \\ z_{1}(t) \\ z_{2}(t) \\ z_{2}(t)\end{array}\right]_{\max }$

The maximum shear forces are obtained from: 
$\left[\begin{array}{l}V_{1}^{2} \\ V_{2}^{2}\end{array}\right]_{\max }=\left[\begin{array}{ll}V_{11} & V_{12} \\ V_{21} & V_{22}\end{array}\right]\left[\begin{array}{ll}V_{11} & V_{21} \\ V_{12} & V_{22}\end{array}\right]$

To illustrate the procedure numerically, assume it is required to determine for the building frame shown in Figure 8 the maximum displacements and base shear forces. The building parameters are $\left(\mathrm{h}_{1}\right)=6 \mathrm{ft},\left(\mathrm{h}_{2}\right)=15 \mathrm{ft}$ and $(\mathrm{L})=30$ $\mathrm{ft}$. The column size is $\mathrm{W} 10 \mathrm{x} 45$. The equivalent floor stiffness $\left(\mathrm{EI}_{1}\right)_{\text {eqv }}=7.44 \times 10^{9} \mathrm{Ib}_{-1 n^{2}}$ and $\left(\mathrm{EI}_{2}\right)_{\text {eqv }}=3.2 \times 10^{9} \mathrm{Ib}-\mathrm{in}^{2}$. Total first level floor load $\left(\mathrm{P}_{1}\right)=52 \mathrm{kip}$ and the second level is $\left(\mathrm{P}_{2}\right)=25.5 \mathrm{kip}$. The blast load at the joints are $\left(\mathrm{F}_{\mathrm{e} 1}\right)_{\text {net }}=10$ kip and $\left(\mathrm{F}_{\mathrm{e} 2}\right)_{\text {net }}=20$ kip. Blast duration $\left(\mathrm{t}_{\mathrm{d}}\right)=0.1 \mathrm{sec}$. The non-dimensional parameters are $(\delta)=3825,(\beta)=701,874$. Accordingly, the building natural frequency parameters are $\left(\omega_{1}\right)=13.9 \mathrm{rad} / \mathrm{s}$ and $\left(\omega_{2}\right)=60.26 \mathrm{rad} / \mathrm{s}$. The natural periods are determined as $\left(\mathrm{T}_{1}\right)=0.45 \mathrm{sec}$ and $\left(\mathrm{T}_{2}\right)=0.1 \mathrm{sec}$. The dynamic load factors are therefore $\left(\mathrm{DLF}_{1}\right)_{\max }=0.57$ and $\left(\mathrm{DLF}_{1}\right)_{\max }=1.22$. The maximum sway deflection $\left(\mathrm{y}_{2}\right)_{\mathrm{Max}}=0.9$ in. Maximum base shear of the building can be computed using Eq.(16) as $\left(\mathrm{V}_{1}\right)_{\max }=8.04 \mathrm{kip}$ and $\left(\mathrm{V}_{2}\right)_{\max }=5.80 \mathrm{kip}$. Accordingly, the total base shear $\left(\mathrm{V}_{\text {total }}\right)=13.84$ kip

\subsection{Global Response Limits}

Performance criteria specify the limits on the dynamic response for (BRB) in order to achieve blast design objectives. Generally, the more deformation the building component is able to undergo without failure, the more blast energy that can be absorbed. In blast dynamic analysis, the structural response is governed by the member ductility. Therefore, response limits are typically placed on the maximum dynamic deflection.

Damage classification currently used in the industry provides high level global definition for building response. The common performance or response criteria used for (BRB) are; a) Low Response; b) Moderate Response and c) High Response. In category (a) localized building damage is allowed. In category (b) larger or widespread damage is allowed. In category (c) severe global damage or collapse is permitted in the post blast event.

Table 1 provides recommendations to maximum dynamic sway deflection for the three performance criteria. Overall building height measured from the ground elevation (GE) is denoted by $(\mathrm{H})=\left(\mathrm{h}_{1}+\mathrm{h}_{2}\right)$. The maximum sway should not exceed (2\%) for buildings designed for low response. These limits are increased to $(4 \%)$ for high response.

Table 1. Proposed Sway Deflection Limits for BRB

\begin{tabular}{|c|c|c|c|}
\hline $\begin{array}{c}\text { Sway Deflection } \\
\text { Limits }\end{array}$ & Low Response & Medium Response & High Response \\
\cline { 2 - 4 } & $\mathrm{H} / 50$ & $\mathrm{H} / 35$ & $\mathrm{H} / 25$ \\
\hline
\end{tabular}

\section{Foundation Systems}

Several foundation systems can be used to support mobile industrial buildings. Figure 9 shows two possible foundation schemes that can be used to support mobile buildings. If the soil bearing capacity is adequate, the foundation system option (I) shown in Figure 9a can be used. The building in this case is placed on mat foundation with concrete pedestals projected to the predetermined installation elevation, as shown in Figure 9a. The longitudinal skid beams are anchored to the concrete pedestals. Fixed or pinned boundary conditions can be used to stimulate the connection to the foundation.

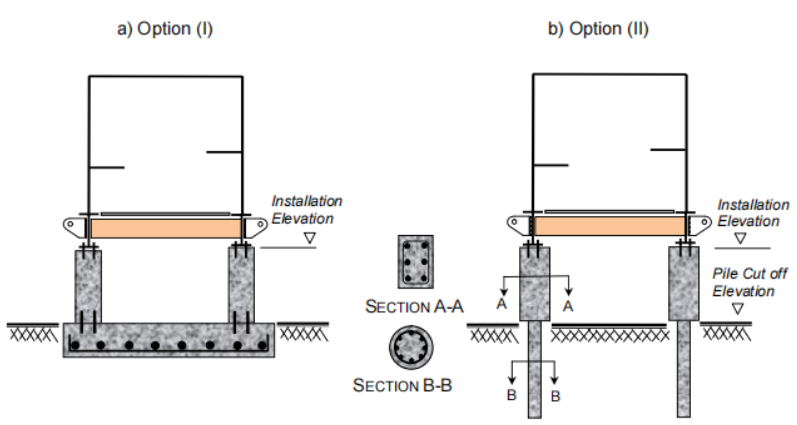

Figure 9. Support System

Figure $9 \mathrm{~b}$ shows alternative foundation option (II) that can be used for weak soil conditions. Rectangular or circular concrete pedestals can be used, in this case, to support the electrical building. The pedestals are projected from the underground piles at the cut-off up to the installation elevation. Section A-A of Figure $9 \mathrm{~b}$ shows typical reinforced rectangular concrete pedestal and section B-B shows typical circular pile section. Determination of pile size and length should be based upon the soil characteristics and geotechnical recommendations. If the stiffness of the hard soil stratum is not adequate to provide fixed end bearing to the pile base, vertical restraints must be used in structural analysis model. In this case, pile capacities are estimated by combining skin friction resistance and soil end bearing.

\section{Transportation Vehicles}

It is recommended to use Self Propelled Module Trailer (SPMT) to transport industrial facilities located on irregular terrains. The vehicle contains a computer system that monitors and controls the motion of the substation during transportation. A schematic of typical SPMT plan and elevation is illustrated in Figure 10. The platform width is $2.43 \mathrm{~m}$ and the length can be variable depending upon the number of axel lines used. For example, SPMT platform length of the using six axle lines is $8.4 \mathrm{~m}$, 
as shown in Figure 10. Each wheel in the SPMT adjust independently to allow it to turn or even spin in place, to make it possible to adjust the SPMT's directions accurately. During transportation, the hydraulic rams allow the SPMT wheels to telescope independently so that the structure is kept flat while moving over uneven or sloped roads. This feature keeps the load distribution on each wheel unchanged, and minimizes the possibility of sliding when driving over slopping surfaces. The operating SPMT speed ranges between $3-5 \mathrm{~km} / \mathrm{hr}$ can be adjusted as required.

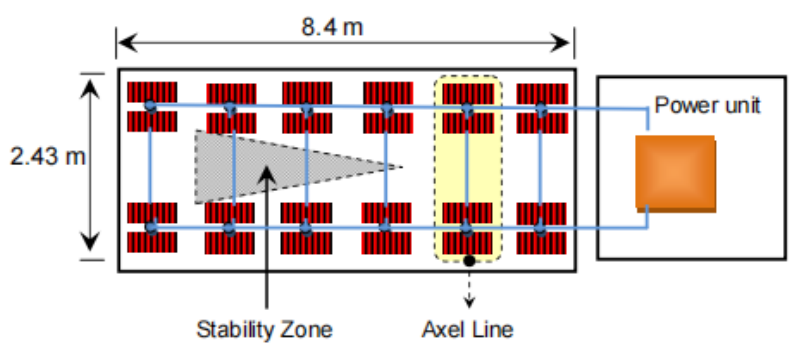

Figure 10. SPMT Vehicle Layout

The center of mass for the transported structure must be located within the triangular stability zone. The coordinates of the triangular stability zone of the SPMT is determined by the manufacture specifications and must be provided prior to relocation. For large electrical substations, several SPMT's trailers are coupled side to side or end to end to match the facility configuration and engineering requirements. The coordinates of the stability zone for the assembled SPMT's varies and depends upon the trailers layout. It must be noted that alignment of substation center of mass within SPMT's stability zone is a challenging task that must be addressed during relocation design cycle.

\section{Impact Load Factors}

Modularization of industrial buildings is a cost effective procedure that results into to significant savings. However, major disadvantages in using modular buildings are the increase in the engineering activities and material cost. The substation modules are required to be designed for lifting and transportation conditions which require using heavier steel sections. This increase in the steel quantity is estimated to be around $40 \%$. Impact loads induced during transportation and lifting should be considered in addition to the operational conditions. Equivalent static analysis procedure can be used to approximate the induced impact loads during transportation.

Lifting details of typical modularized building are shown in Figure 11a. Four or eight lifting points can be used depending upon the building size. The steel skid must be designed to accommodate lifting loads with an appropriate factor of safety. It is recommended to use removable lifting lugs as shown in Figure 11b. Lifting lugs are installed on the longitudinal beam webs along the column grids using end plate bolted connections. It is also recommended to use the same connection type for the transverse beams. Reinforcing plates (shown in detail E) might be required to be welded around the lifting lug hole on both sides to enhance stiffness at the stress concentration regions. The lifting lugs should be designed according to the shackle capacity used by the lifting crane. The size of the lifting hole must match the lifting pin size. Also the edge distance must be sufficient to prevent failures. The lifting lugs must be checked against combined tension and shear block failures using design factor of safety 5 . The connecting bolts should also be checked against combined shear and tension failures.

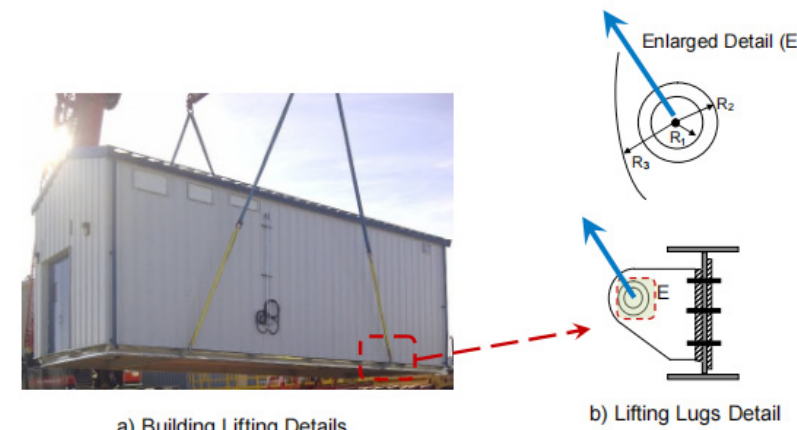

Figure 11. Illustration of Lifting Details of modular Building

\section{Jacking of Electrical Buildings}

Hydraulic jacking can be used to relocate existing mobile buildings at the end of the project. The buildings are first decommissioned and disassembled from the existing foundation at the original location, then transported to re-use at the new plant location. Therefore, the building is required to be designed for upward jacking as well. Figure 12 illustrates schematically the overall procedure. SPMT trailers with adjustable platforms are first placed between the concrete pedestals. Then hydraulic jacking can be used to raise the base frame support up to the desired elevation. This step becomes very complicated if the building contains heavy equipments or composed of several units. Also un-symmetric distribution of mass within the facility may offset the centre of mass (CM) and complicates jacking procedure and transporting vehicle layout. 


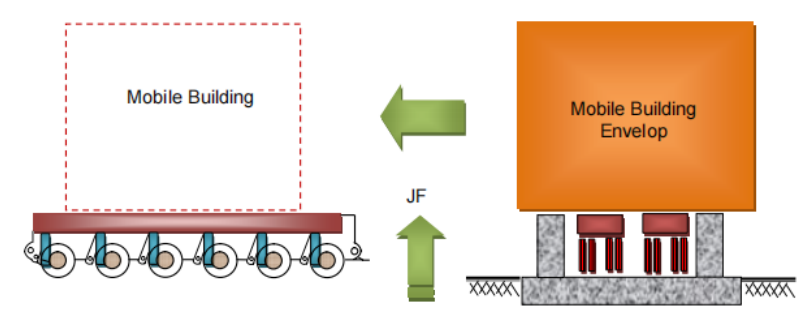

Figure 12. Jacking and Relocation of Electrical Substation

Upward jacking of electrical substation is accomplished using hydraulic stool system. The magnitude of the jacking forces (JF) is determined by the construction contractors based on weight and combined centre of mass location. Accurate calculation of combined (CM) coordinates is very critical and must be computed accurately to avoid failures during jacking or transportation. Engineering models must be developed prior to execution. Therefore, the magnitude of the jacking forces used by the construction contractor must be provided to the design engineer prior to execution. The computation of the center of mass (CM) for the transported electrical substations must include structural steel members, mechanical and electrical equipment, cable trays and electrical cabinets.

\section{Design Guidelines}

The initial building model is normally developed by several disciplines during the front end engineering phase. The model should be tested against critical load conditions including operation, lifting, jacking and transportation cases. The structural model must be continuously updated prior to execution and tested for serviceability and ultimate limit states (SLS and ULS) for disassembly, transportation, and installation. Structural stability of the building should be examined and peak dynamic displacements shall be determined by accounting for material non-linearity and P- $\Delta$ effect.

Structural components of mobile building shall be designed for strength and serviceability limit states in accordance to local codes requirements. Members should be checked with each type of loading in order to determine the most severe load condition. Interior equipment connections must also be examined for relocation. It must be noted that some vendors designs may not account for the impact forces induced during relocation. The engineer should also explore possible options to reinforcing weak connections or critical members. The structural model update must also include the new members or structural reinforcements.
Sub-models are then generated to examine the structural serviceability ultimate limit states (SLS \&ULS). It must be noted that the boundary conditions and applied loads that are used in these models are different. The engineer must verify (SLS) and (ULS) during the jacking and disassembly procedures. Temporary supports that will be used during the jacking procedure must also be incorporated in this model. Determination and points of applications of the impact factors during the jacking is also very essential. The engineer must idealize points of contact between the structural framing and the jacking stools.

The transportation roads that will be used by the SPMT's must also be inspected prior to mobilization. Soil strength in some projects may not be capable to sustain the combined SPMT and the structure. Survey to the existing slopes must be performed to identify the profile changes following several years of operation. It must be noted that in many project sites transportation rods are constructed using compacted layers of gravel, and the changes in the road profile or condition are very common. Obstructions to the SPMT's manoeuvres must also be identified.

The engineer must also examine structural (SLS) and (ULS) during lifting and installation procedures. Artificial boundary conditions might be required to stabilize the structural analysis model. Appropriate safety factors must be used during the crane lifting and installation.

\section{Conclusions}

This paper presented economical concepts for design of electrical substations and control buildings. Limited literature and guidelines are available in practice for various design aspects for this class of buildings. The paper overviewed the structural layouts of typical electrical substations. The economical aspects and cost savings resulting in using relocatable electrical buildings were also discussed. The paper also highlighted various engineering challenges that are encountered in the design of mobile industrial facilities. The transportation procedure and design requirements were briefly described. Recommendations were provided to compute the combined center of mass of the substation and interior equipment. Effective analysis procedure is also described. The proposed design concept for mobile buildings is cost effective and can be implemented in industry to reduce projects cost.

Current building codes are not adequate for design of BRB. Additional guidelines and design provisions are required to accurately define blast loading parameters and set limitations on BRB dynamic response. Unfor- 
tunately, little design rules are available in practice for this class of buildings that are extensively used in the industry. The paper presented MDOF dynamic model to evaluate dynamic response of industrial BRB. The loading conditions and structural design criteria of BRB were briefly described. The mathematical derivations to compute the global displacement and base shear were presented. Building example was then provided to illustrate the computation procedure. The paper provides useful tools that can be used in industry to calculate BRB dynamic response with little computation effort compared to numerical FE or CFD models. Structural response can be calculated manually using formulas of section (5.2).

Effective BRB structural system should be capable to absorb and dissipate the blast explosion energy while maintaining the structural integrity. The building must have adequate ductility and strength to resist lateral loads resulting from the blast wave. The limits of Table 1 can be used as guidance to define the level of damage acceptable for blast resistant building.

Damage classification procedures used in the industry for BRB are not economical since it is based on the overall building response. For example, local failures BRB is not permitted for secondary members. Therefore, it is more economical to establish alternative local damage classification procedure. It is also recommended to standardize the design of BRB according to the magnitude of blast pressure and impulse duration.

\section{References}

[1] Bedair, O. (2020), "Economical Damage Classification Procedure for Blast Resistant Buildings in Petrochemical Plants", ASCE, Practice Periodical on Structural Design and Construction,25(3),04020020.

[2] Bedair, O. (2015) "Novel Design Procedures For Rectangular Hollow Steel Sections (RHSS) Subject To Compression, Major \& Minor Axes Bending", ASCE, Practice Periodical on Structural Design and Construction , 20, 04014051.

[3] Bedair, O. (2014) "Cost Effective Modularization Strategies for Industrial Facilities Used in Mega Oil\&Gas Projects" Recent Patents on Engineering, 8, pp.120-132.

[4] Bedair,O. (2014) "Rational Design of Pip-Racks Used For Oil Sands and Petrochemical Facilities", ASCE, Periodical on Structural Design and Construction, 20 (2), 04014029.

[5] Bedair, O. (2014) "Modern Steel Design and Construction Used In Canada's Oil Sands Industry" Journal of Steel Design Construction and Research",

\section{7 (1), pp.32-40.}

[6] Bedair, O. (2012) "Interaction of Multiple Pipe Penetrations Used In Mining and Petrochemical Facilities", Journal of Thin-Walled Structures, 52, 158164.

[7] Newman, A. M., Rubio, E., Caro, R., Weintraub, A., and Eurek, K. (2010) "A review of operations research in mine planning" Interfaces, 40(3), 222245.

[8] Burt, C. \& Caccetta, L. (2007) "Match factor for heterogeneous truck and loader fleets", International Journal of Mining, Reclamation and Environment, 21(4), 262-270.

[9] Alarie, S, and Gamache, M. (2002) "Overview of solution strategies used in truck dispatching systems for open pit mines",International Journal of Surface Mining, Reclamation and Environment, 16(1),5976.

[10] Soumis, F., Ethier, J., and Elbrond (1989) "Truck dispatching in an open pit mine. International", Journal of Surface Mining Reclamation and Environment, 3(2), 115-119.

[11] AISC (2006), "Steel Construction Manual", 14th Edition. American Institute of Steel Construction, Chicago, USA.

[12] AISI (2007), "North American Specification for the Design of Cold-Formed Steel Structural Members", American Iron Steel Institute, Washington DC, USA.

[13] ASCE/SEI 7-10 7 (2010) "Minimum Design Loads and other structures", American Society of Civil Engineers, Virginia, USA.

[14] AASHTO LRFD Bridge Design Specifications, (2012) American Association of State Highway and Transportation "- Customary US units " AASTO Publications, Washington.

[15] CAN/CSA-S136-07 (2007) "North American Specification for the Design of Cold-Formed Steel Structural Members", Canadian Standard Steel Association, Mississauga, Ontario.

[16] CAN/CSA-S16-01 (2010) "Limit states design of steel structures", Canadian Standards Association, Mississauga, Ontario, Canada.

[17] NRC (National Research Council of Canada). 2010. National building code. Ottawa, ON: National Research Council of Canada.

[18] Eurocode 3: (2005) Design of steel structures Part 1.5: plated structural elements; EN 1993-1-5: 2005.

[19] Process Industry Practices-PIP STC01015, (2014) "Structural design Criteria", Texas, USA.

[20] Ziemian, R. (2010) "Guide to Stability Design Criteria for Metal Structures", 6th edition, John Wiley 
and Sons Ltd.

[21] Coughlin AM, Musselman ES, Schokker AJ, Linzell DG. (2010) " Behavior of portable fiber reinforced concrete vehicle barriers subject to blasts from contact charges" International Journal of Impact Engineering; 37(5): 521-529.

[22] Remennikov AM. (2003) A review of methods for predicting bomb blast effects on buildings. J Battlefield Technol 6(3):5-10.

[23] Remennikov AM, Rose TA. (2005) Modelling blast loads on buildings in complex city geometries. Int $\mathrm{J}$ Comput Struct;83, 2197-2205.
[24] US Army Corps of Engineers TM 5-1300 (1990) "Structures To Resist The Effects Of Accidental Explosions", New York, USA.

[25] ASCE (2010) "Design of Blast Resistant Buildings in Petrochemical Facilities" ASCE Petrochemical Committee, Task Committee on Blast Resistant Design, New York.

[26] CSA S850-12, (2017) "Design and Assessment of Buildings Subjected to Blast Loads" Canadian Standard association, Toronto, Canada.

[27] Process Industry Practices PIP STC 01018 (2014) "Blast Resistant Building Design Criteria”, USA. 